\title{
Islets of Langerhans Are Protected from Inflammatory Cell Recruitment during Reperfusion of Rat Pancreas Grafts
}

\author{
G. Preissler $^{a, b}$ S. Massberg ${ }^{b, d}$ M.E. Eichhorn ${ }^{a, b} \quad$ H. Waldner ${ }^{c} \quad$ F. Loehe ${ }^{a, e}$ \\ H. Winter ${ }^{\mathrm{a}}$ K. Messmer \\ ${ }^{a}$ Department of Surgery, ${ }^{b}$ Institute for Surgical Research, Walter-Brendel Centre for Experimental Medicine, \\ Klinikum Grosshadern, Ludwig Maximilians University of Munich, 'Department of General and Visceral \\ Surgery, Munich Schwabing Hospital, dDeutsches Herzzentrum, Technische Universität München, Munich, and \\ e Department of General, Visceral and Thoracic Surgery, Klinikum Landshut, Landshut, Germany
}

\section{Key Words}

Pancreas transplantation - Microcirculation - Leukocytes • Islets of Langerhans $\cdot$ Ischemia/reperfusion

\begin{abstract}
Background: Ischemia/reperfusion (I/R) injury plays a pivotal role in the development of graft pancreatitis, with ischemia time representing one of its crucial factors. However, it is unclear, whether exocrine and endocrine tissue experience similar inflammatory responses during pancreas transplantation (PTx). This study evaluated inflammatory susceptibilities of islets of Langerhans (ILH) and exocrine tissue after different preservation periods during early reperfusion. Methods: PTx was performed in rats following $2 \mathrm{~h}(2 \mathrm{~h}-\mathrm{l})$ or $18 \mathrm{~h}(18 \mathrm{~h}-\mathrm{I})$ preservation. Leukocyte-endothelial cell interactions (LEI) were analyzed in venules of acinar tissue and ILH in vivo over $2 \mathrm{~h}$ reperfusion. Nontransplanted animals served as controls. Tissue samples were analyzed by histomorphometry. Results: In exocrine venules leukocyte rolling predominated in the $2 \mathrm{~h}-\mathrm{I}$ group. In the $18 \mathrm{~h}$-I group, additionally, high numbers of adherent leukocytes were found. Histology revealed significant edema formation and leukocyte
\end{abstract}

extravasation in the 18h-I group. Notably, LEl in postcapillary venules of ILH were significantly lower. Leukocyte rolling was only moderately enhanced and few leukocytes were found adherent. Histology revealed minor leukocyte extravasation. Conclusion: Ischemia time contributes decisively to the extent of the I/R-injury in PTx. However, ILH have a significantly lower susceptibility towards $I / R$, even when inflammatory reactions in adjacent exocrine tissue are evident.

Copyright $\odot 2010$ S. Karger AG, Basel

\section{Introduction}

Pancreas transplantation (PTx) is severely compromised by graft pancreatitis and thrombosis [1], which occur in up to $20 \%$ of all patients and lead to graft loss in about $7-10 \%$ of cases [2]. Besides donor organ quality and recipient specific factors, particularly prolonged preservation time [3] seems to induce alterations to microvascular endothelial cells in the graft, which augment the ischemia/reperfusion (I/R) injury after transplantation [4]. The microvasculature of the pancreas graft presents the first target site, interacting immediately with recipi-

\section{KARGER}

Fax +41613061234 E-Mail karger@karger.ch www.karger.com
(C) 2010 S. Karger AG, Base

$0014-312 \mathrm{X} / 10 / 0444-0192 \$ 26.00 / 0$

Accessible online at:

www.karger.com/esr
Dr. med. Gerhard Preissler

Department of Surgery, Chirurgische Klinik und Poliklinik - Klinikum Grosshadern Ludwig Maximilians University of Munich

Marchioninistrasse 15, DE-81370 Munich (Germany)

Tel. +49 897095 2709, Fax +49897095 5706

E-Mail gerhard.preissler@med.uni-muenchen.de 
ent blood cells and promoting the initiation and progression of the inflammatory processes [5].

In addition to tissue resident cells such as macrophages and dendritic cells [6, 7], local inflammatory responses are essentially elicited via invading blood-born leukocytes [8]. Briefly, leukocyte-endothelial cell interactions (LEI) are characterized by an overlapping three-step cascade beginning with temporary adhesion of leukocytes to the vessel wall of postcapillary venules ('rolling'), followed by firm adhesion ('sticking') and finally extravasation of the leukocytes into the tissue [9]. Specific adhesion molecules (selectins, integrins, immunoglobulin superfamily), localized on the surface of leukocytes and the endothelium, are involved in these cellular interactions. Besides a network of hormones, chemokines and cytokines, their expression is initiated by free oxygen radicals, released immediately after reintroduction of molecular oxygen to the graft [10]. In parallel, increased macromolecular endothelial permeability allows protein extravasation and concomitant fluid shift to the extravascular space. The resulting interstitial edema contributes to a critical reduction of the nutritive microcirculation in postischemic graft tissue $[11,12]$.

Distribution and concentration of endothelial surface molecules display vast heterogeneities among organs [13]. Although a diverse expression of adhesion molecules in exocrine versus endocrine pancreas has not been identified so far, phage display analysis revealed that peptide ligands on acinar endothelium and endothelium of the islets of Langerhans (ILH) differ from each other by more than $80 \%$ [14]. Additionally, it has been demonstrated that microvascular blood flow in ILH is higher when compared to exocrine tissue $[15,16]$. In fact, ILH appear relatively hyperperfused, providing them with a functional reserve to ensure metabolic homeostasis for the whole organism [17]. Thus, intensity of LEI as well as susceptibility towards I/R might be different in the ILH as compared to the exocrine tissue.

A case-in-point is the clinical observation that a sudden rise of blood glucose concentrations, accompanied by a drop of C-peptide levels, often precedes the symptoms of graft pancreatitis and thrombosis, suggesting a higher sensitivity of the islet apparatus [18]. On the other hand, experimental studies that directly quantified postischemic microvascular damage point to a higher tolerance of the ILH towards I/R, when compared to the exocrine tissue [19]. Hence, the susceptibility of the exocrine versus the endocrine pancreas during transplantation still remains controversial. Here, we addressed this open question and directly analyzed inflammatory leukocyte accumulation in the microcirculation of exocrine and endocrine tissue of pancreas grafts using intravital fluorescence microscopy (IVM) following short- and long-term hypothermic preservation, respectively.

\section{Material and Methods}

The experiments were approved by the local government and carried out at the Institute for Surgical Research at Munich University, Walter-Brendel-Centre for Experimental Medicine, in accordance with the 'Principles of Laboratory Animal Care' of the NIH publication Vol. 25, No. 28, revised 1996.

\section{Anesthesia and Surgery}

Inbred male Lewis rats $(\mathrm{n}=35)$ weighing $198 \pm 5 \mathrm{~g}$ were used in this study. After overnight fasting, but free access to tap water, animals were anesthetized with chloralhydrate $(360 \mathrm{mg} / \mathrm{kg}$ i.p.), tracheotomized and mechanically ventilated with an oxygen/nitrous-oxide mixture (ventilatory rate $50-60 / \mathrm{min}$, tidal volume 10 $\mathrm{ml} / \mathrm{kg}$, inspiration/expiration ratio $1: 1$, airway pressure $<5 \mathrm{~mm}$ $\mathrm{Hg}, \mathrm{FiO}_{2}=0.3-0.35$; Harvard Rodent Ventilator 683, Harvard Apparatus, Mass., USA) for maintenance of normal arterial blood gases. Adequate anesthesia was achieved throughout the experiments by intravenous infusion of $\alpha$-chloralose $(20 \mathrm{mg} / \mathrm{kg} / \mathrm{h})$. The left carotid artery and jugular vein were cannulated with polypropylene catheters (PE-50; $0.58 \mathrm{~mm}$ i.d.; Portex, Hythe, UK) for continuous recording of mean arterial blood pressure (MABP) and heart rate (HR) as well as for fluid replacement $(4 \mathrm{ml} / \mathrm{h} \mathrm{NaCl}$ i.v.) and injection of the fluorescent compounds in the recipients. Body temperature was maintained between $36-37^{\circ} \mathrm{C}$ by placing the animals in supine position on a heating pad.

Recovery of the pancreaticoduodenal graft was performed according to a modified technique described by Lee et al. [20] in detail. The donor operation was accomplished using a 'no touch' technique, thus direct manipulations of the pancreas could be avoided. A saran wrap was used to keep the tissue moist and to reduce the influence of ambient air. Briefly, pancreas and duodenum were mobilized at an aortal segment including celiac trunk and superior mesenteric artery. Following heparinization (200 IE i.v.) the aorta was cannulated, the portal vein cut at the bifurcation and the pancreas flushed with $10 \mathrm{ml}$ chilled University of Wisconsin solution (UW; pressure: $50 \mathrm{~cm} \mathrm{H}_{2} \mathrm{O}$; Belzer UW-CSS, Du Pont Pharmaceuticals, Wilmington, Del., USA). After dissection of the aortal segment, the graft was removed from the donor and stored for either 2 or $18 \mathrm{~h}$ in $4^{\circ} \mathrm{C}$ cold UW solution, respectively.

In the recipient, the left kidney was removed and the pancreaticoduodenal graft anastomosed to the renal vessels using a nonsuturing cuff technique. After simultaneous release of the clamps, the pancreaticoduodenal graft was carefully exteriorized on a specially designed stage for IVM. The pancreatic surface was covered with saran wrap and superfused with warm, bicarbonatebuffered Ringer's solution. Exocrine secretions were allowed to flow off via a catheter placed in the distal part of the duodenum.

\section{Experimental Protocol}

Recipient animals of the short-term preservation group received pancreas grafts following $2 \mathrm{~h}$ ischemia $(2 \mathrm{~h}-\mathrm{I} ; \mathrm{n}=7)$ in cold UW solution, whereas animals of the long-term preservation 
group received pancreas grafts after $18 \mathrm{~h}$ hypothermic ischemia $(18 \mathrm{~h}-\mathrm{I} ; \mathrm{n}=7)$ stored in the same solution. Seven nontransplanted animals served as controls. After laparotomy and dissection of the ligaments surrounding the duodenum, pancreas and spleen, their native pancreas was exteriorized on the stage for IVM. When the recipient animals met the entry criteria (MABP $80-120 \mathrm{~mm} \mathrm{Hg}$; $\mathrm{paO}_{2}=100-130 \mathrm{~mm} \mathrm{Hg} ; \mathrm{paCO}_{2}=35-40 \mathrm{~mm} \mathrm{Hg}$ ), revascularization and reperfusion were commenced. Warm ischemia time during revascularization lasted $11 \pm 1 \mathrm{~min}$ and did not differ significantly between the two transplantation groups. Macrohemodynamic parameters were continuously monitored. Microcirculatory analyses were performed 30,60 and $120 \mathrm{~min}$ after onset of reperfusion or exteriorization of the native pancreas in control animals, respectively. Peripheral leukocyte cell counts were determined at the beginning and end of the experiments (Coulter Counter T 540, Coulter Electronics, Hialeah, Fla., USA). All animals survived the 120-min reperfusion period. At the end of the observation period animals were sacrificed and tissue samples from the grafts were taken for histological analysis.

\section{Intravital Fluorescence Microscopy}

Intravenous injection of $0.1 \mathrm{ml}$ fluorescein isothiocyanate (FITC)-labeled hydroxyethyl starch (0.75\%; MW 200,000/0.6; Laevosan, Linz, Austria) and $0.1 \mathrm{ml}$ rhodamine-6G (0.2\%; MW 479; Sigma, St. Louis, Mo., USA) allowed for contrast enhancement of microvessels and in vivo staining of leukocytes for IVM, respectively. A modified Leitz-Orthoplan microscope (Leitz, Wetzlar, Germany) with a $100 \mathrm{~W}$ HBO lamp, attached to a Ploemo-Pak illuminator with $\mathrm{I}_{2 / 3}$ (excitation 450-490 nm/emission $>515 \mathrm{~nm}$ ) and $\mathrm{N}_{2}$ (excitation $530-560 \mathrm{~nm} / \mathrm{emission}>580$ $\mathrm{nm}$ ) filter blocks was used for epi-illumination. To avoid phototoxic effects induced by IVM [21], light exposure was limited to $30 \mathrm{~s}$ for each observation interval. A water immersion objective (W $25 \times / 0.6$, Leitz) facilitated a final magnification $820 \times$ on the video screen (PVM 2042 QM, Sony, Germany). The observations were recorded by means of a charge-coupled device video camera (FK 6990, COHU; Prospective Measurements, San Diego, Calif., USA) and transferred to a S-VHS video recorder (AG-7330, Panasonic, Tokyo, Japan) for offline evaluation.

\section{Microcirculatory Analysis}

Quantitative analysis of the microcirculation of pancreas grafts included the determination of LEI in postcapillary venules of the exocrine tissue and in draining venules of the ILH. On average, 3-6 exocrine venules or ILH venules were observed per animal, respectively. ILH were identified by their glomerulumlike framework of capillaries and their brighter fluorescence when compared with the surrounding acinar tissue. Leukocytes rolling along the vessel wall are given as percentage of all leukocytes passing through the observed segment within $30 \mathrm{~s}$. Adherent leukocytes (stickers) that did not detach from the endothelial lining within an observation period of $30 \mathrm{~s}$ are given as number of cells per $\mathrm{mm}^{2}$ of endothelial surface, calculated from diameter and length of the vascular segment studied [11].

\section{Histology}

Pancreatic tissue was fixed in $4 \%$ paraformaldehyde, embedded in paraffin, sectioned and stained with chloroacetate-esterase/eosin for light microscopic analysis. Leukocyte infiltration into tissue was analyzed histomorphologically by counting ex- travasated chloroacetate-esterase stained leukocytes in $60 \mathrm{HPF}$ $\left(\mathrm{n} / \mathrm{mm}^{2}\right)$ per animal. Interstitial edema formation was assessed by a planimetric area analysis (percentage edema area of total tissue area) in $60 \mathrm{HPF}$ per animal.

\section{Statistics}

Results are expressed as means \pm SEM. Raw data from LEI analysis and from the histological measurements were averaged for each animal and time point, respectively, before they entered statistical evaluation. Kruskal-Wallis one-way analysis of variance on ranks followed by Dunn's test were applied for the assessment of different groups. For time interactions Friedman repeated measures ANOVA on ranks followed by Dunn's test were used. Differences were considered significant at a $\mathrm{p}<0.05$ level.

\section{Results}

The grafts were reperfused promptly once revascularization was established, as evidenced by the pulsation of the supplying vessels and immediate return of the tissue color to a normal pinkish appearance.

\section{Macrohemodynamics}

MABP, HR and arterial blood gases remained stable throughout the reperfusion period without time or group differences. Leukocyte counts in peripheral blood remained unchanged when compared with control animals (data not shown). All animals maintained normal blood glucose levels throughout the experiment.

\section{Microcirculation in Exocrine Tissue}

Following transplantation, the fraction of rolling leukocytes in postcapillary venules of the exocrine tissue was significantly increased in both transplantation groups during the whole reperfusion period when compared with controls (fig. 1a). The highest rolling fraction was observed $30 \mathrm{~min}$ after the onset of reperfusion, with a decline after 60 and $120 \mathrm{~min}$.

Firmly adherent leukocytes in postcapillary venules of exocrine tissue were significantly increased in the $2 \mathrm{~h}-\mathrm{I}$ group only after 30 min (approximately 4 -fold) in comparison to controls. In contrast, firm leukocyte adhesion was a prominent phenomenon in the $18 \mathrm{~h}-\mathrm{I}$ group (fig. $1 \mathrm{~b}$ ). With an approximate 8- to 16 -fold increase compared to controls, firmly adherent leukocytes in this group were significantly elevated during the whole reperfusion period.

Furthermore, microvascular perfusion in exocrine tissue of both transplantation groups was hallmarked by an alternating complete cessation and resumption of capillary blood flow, termed intermittent capillary perfusion. 


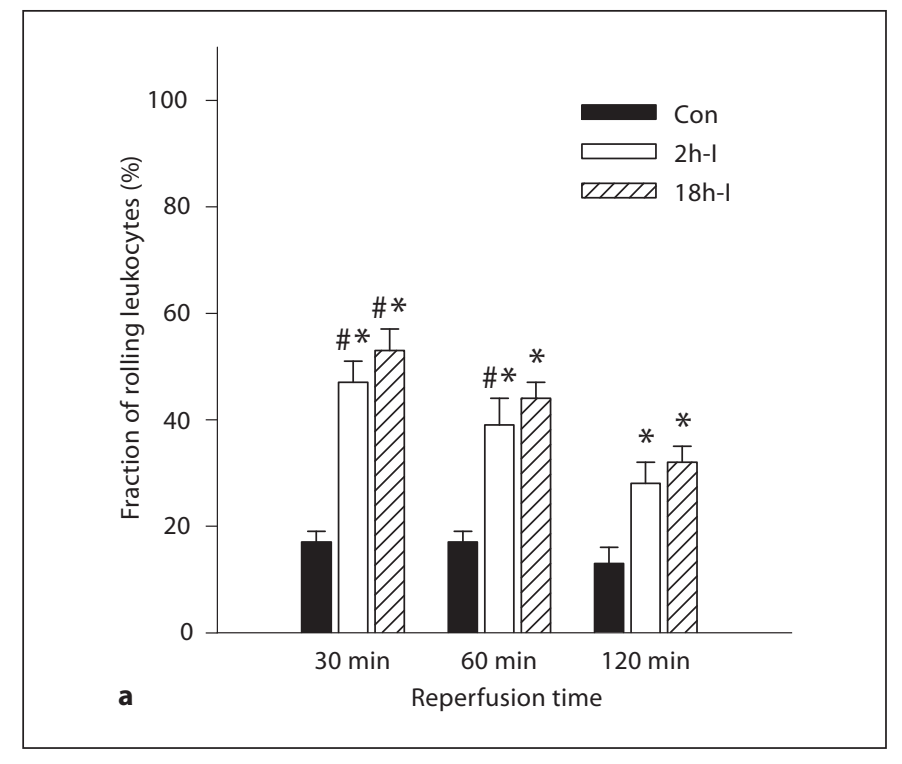

Fig. 1. Fraction of rolling leukocytes (\%) (a) and number of firmly adherent leukocytes $\left(\mathrm{mm}^{-2}\right)(\mathbf{b})$ in postcapillary venules of exocrine tissue of pancreas grafts as examined by intravital fluorescence microscopy. Following either $2 \mathrm{~h}$ (white bars) or $18 \mathrm{~h}$ (hatched bars) hypothermic ischemia, measurements were made after 30, 60 and $120 \mathrm{~min}$ of reperfusion. The native pancreas of

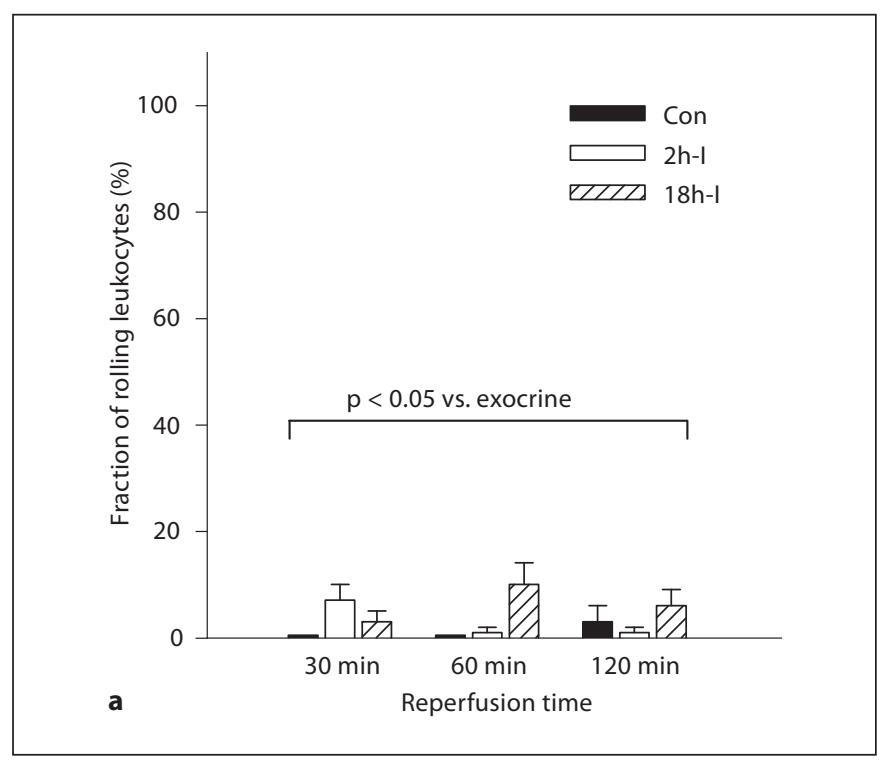

Fig. 2. Fraction of rolling leukocytes (\%) (a) and number of firmly adherent leukocytes $\left(\mathrm{mm}^{-2}\right)(\mathbf{b})$ in postcapillary venules of the islets of Langerhans of pancreas grafts as examined by intravital fluorescence microscopy. Following either $2 \mathrm{~h}$ (white bars) or $18 \mathrm{~h}$ (hatched bars) hypothermic ischemia, measurements were made during $2 \mathrm{~h}$ reperfusion. The native pancreas of nontrans-

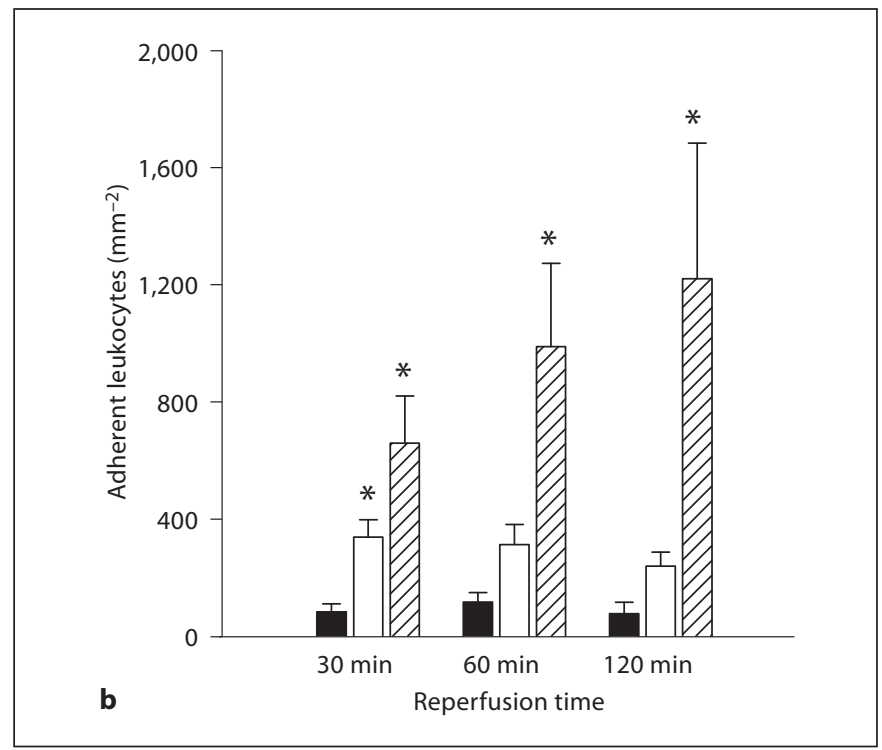

nontransplanted animals served as controls (black bars). Significant rolling was seen in both transplant groups; firmly adherent leukocytes increased in the $18 \mathrm{~h}-\mathrm{I}$ group during reperfusion. Data shown represent mean \pm SEM. ${ }^{*} \mathrm{p}<0.05$ vs. controls, ${ }^{\#} \mathrm{p}<0.05$ vs. $120 \mathrm{~min}$ reperfusion.

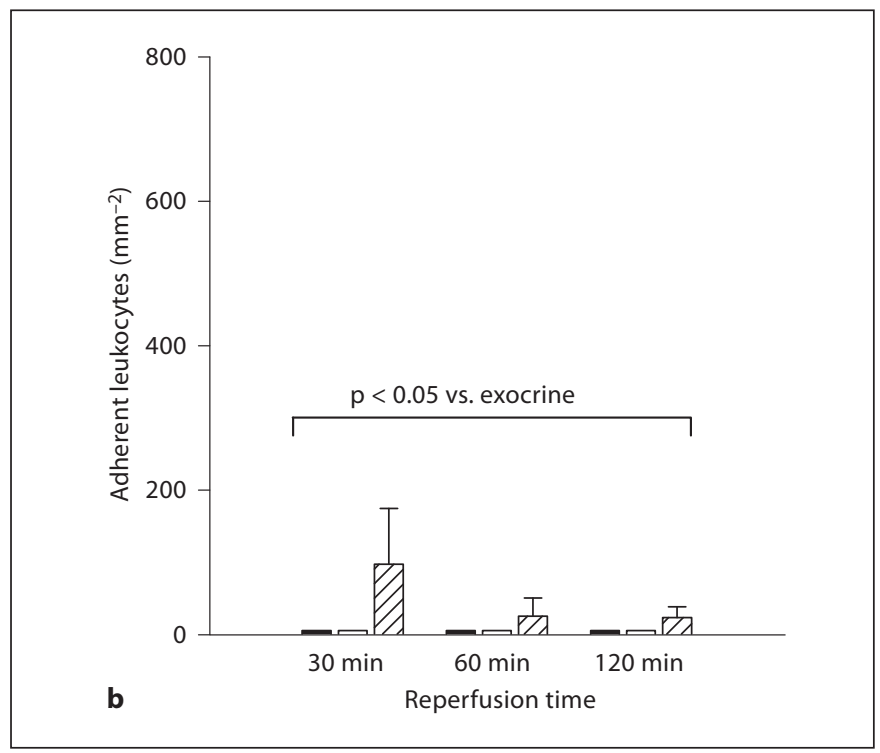

planted animals served as controls (black bars). Only very mild rolling and firm adherence of leukocytes, without group differences, was observed. Compared with LEI in exocrine venules, all data are significantly lower at corresponding observation intervals. Data shown represent mean \pm SEM. 


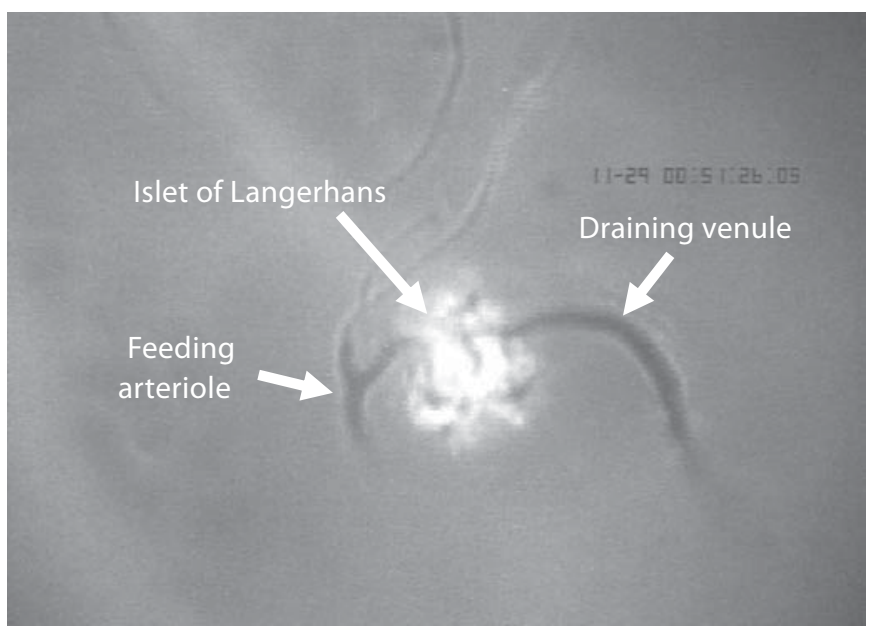

Fig. 3. Intravital microscopic images of pancreas grafts following $18 \mathrm{~h}$ hypothermic preservation and $2 \mathrm{~h}$ reperfusion. The left panel shows an islet of Langerhans following contrast enhancement with FITC-labeled hydroxyethyl starch, which allows visualization of its feeding arteriole and draining venule. The right panel shows an islet of Langerhans with its postcapillary venule

\section{Microcirculation in the Islets of Langerhans}

In contrast to the strong inflammatory response seen in the exocrine tissue, leukocyte accumulation in the endocrine tissue was only moderately increased following transplantation as compared to control. Neither in the $2 \mathrm{~h}-\mathrm{I}$ group nor in the $18 \mathrm{~h}-\mathrm{I}$ group significantly higher LEIs were detected in postcapillary venules of the ILH (fig. 2,3$)$. Rolling fraction in ILH did not exceed a maximum of $7 \pm 3 \%$ in the $2 \mathrm{~h}$-I group (30 min reperfusion) and $10 \pm 4 \%$ in the $18 \mathrm{~h}$-I group (60 min reperfusion). In the control group rolling leukocytes were hardly noted at all (fig. 2a).

Throughout the observation period firmly adherent leukocytes within postcapillary venules of the ILH could not be detected in the control and in the 2h-I group. Only in the 18h-I group were few firm adherent leukocytes seen; however, their numbers did not differ significantly from control animals (fig. 2b). Consequently, both rolling and firm adhesion of leukocytes were significantly lower in all groups in postcapillary venules of the ILH when compared with the exocrine tissue (fig. 1, 2). In contrast to the exocrine tissue, intermittent capillary perfusion was not detected in the ILH.

\section{Histologic Findings}

After transplantation and $2 \mathrm{~h}$ of reperfusion significant leukocyte extravasation was not found in exocrine

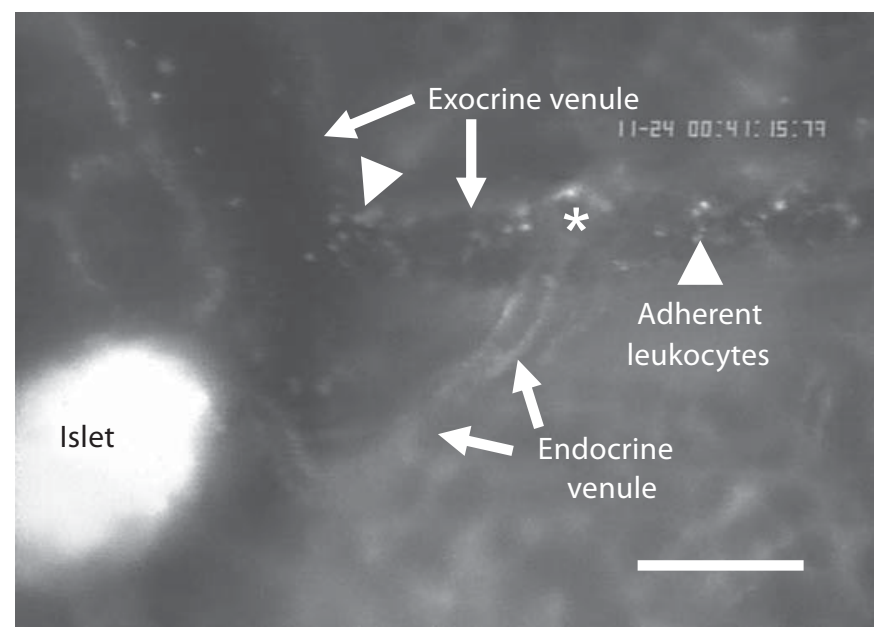

draining into a venule of the exocrine tissue (asterisk). Using contrast enhancement with rhodamine $6 \mathrm{G}$, multiple rolling and firmly adherent leukocytes within the exocrine postcapillary venule are visible (arrowhead), whereas LEI were almost absent in the draining venule of the islet. $\mathrm{Bar}=100 \mu \mathrm{m}$.

tissue of the $2 \mathrm{~h}-\mathrm{I}$ group, but in exocrine tissue of the $18 \mathrm{~h}$ I with an approximately 10 -fold increase compared to controls (fig. 4a, 5). In ILH, leukocyte extravasation was minimal in both transplantation groups and absent in controls. Here, significant difference between ILH and exocrine tissue was observed in the 18h-I group (fig. $4 \mathrm{a}$, 5). Similarly, interstitial edema formation in exocrine tissue was mild in the $2 \mathrm{~h}$-I group and significantly elevated in the 18h-I group compared with controls. In the ILH no interstitial edema formation could be detected histomorphometrically (fig. 4b).

\section{Discussion}

I/R-injury in pancreas grafts is characterized by oxidative stress-related microcirculatory disorders and inflammatory cell invasion $[10,12]$, ultimately mimicking the situation of acute necrotizing pancreatitis of native organs. Based on this feature, earlier studies focused mostly on microcirculatory alterations of the exocrine, rather than the endocrine part of the grafts $[4,22,23]$, although restitution of the endocrine function is the primary goal of pancreas transplantation. In contrast, only few studies examined and compared the microcirculatory alterations associated with I/R-injury of the exocrine pancreas and the ILH. These previous reports mainly 


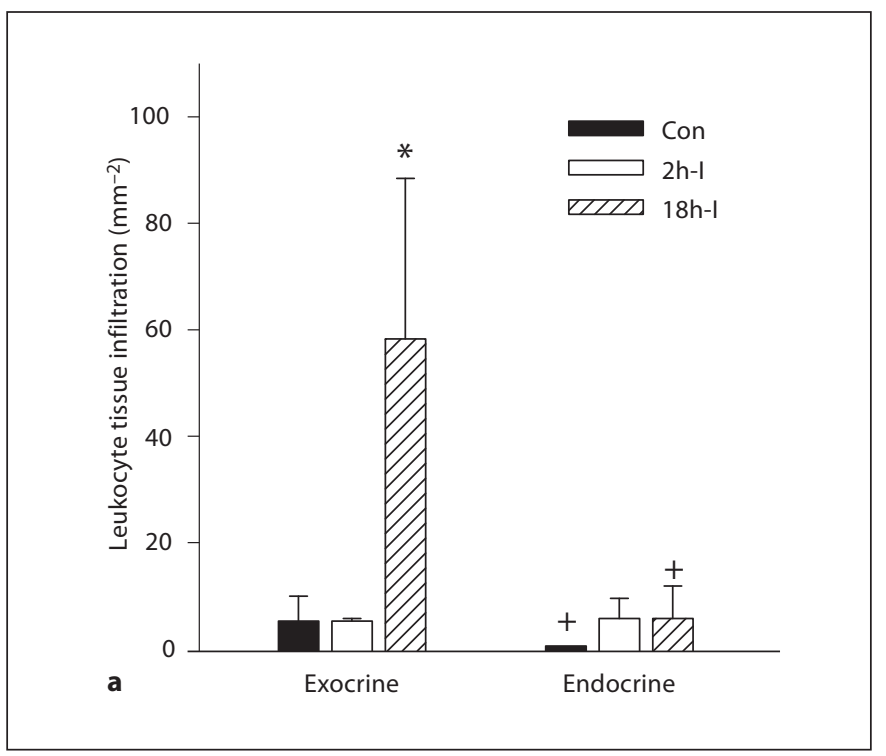

Fig. 4. Leukocyte tissue infiltration $\left(\mathrm{mm}^{-2}\right)$ (a) and edema formation (percentage edema area of total tissue area) (b) in exocrine tissue and islets of Langerhans of controls (black bars), pancreas grafts after $2 \mathrm{~h}$ (white bars) and $18 \mathrm{~h}$ hypothermic (hatched bars) ischemia as measured by histomorphometry. Exocrine tissue

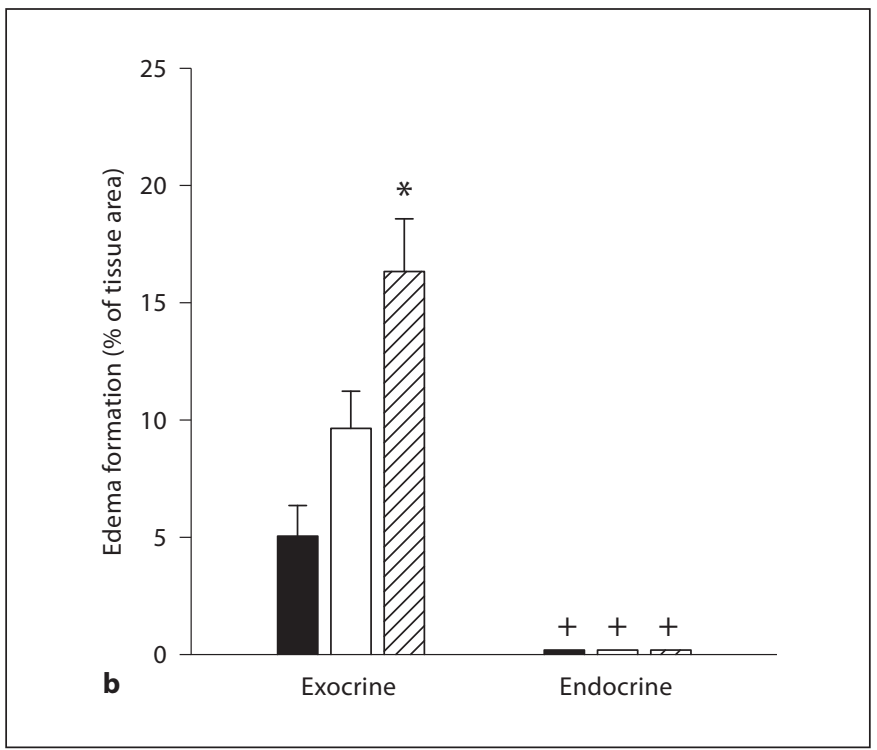

yielded significant leukocyte infiltration and edema formation after 18-hour hypothermic preservation. In contrast, only very mild leukocyte infiltration and no edema formation were noted within the islets of Langerhans. Data shown represent mean \pm SEM. ${ }^{*} \mathrm{p}<0.05$ vs. controls. ${ }^{+} \mathrm{p}<0.05$ vs. exocrine.

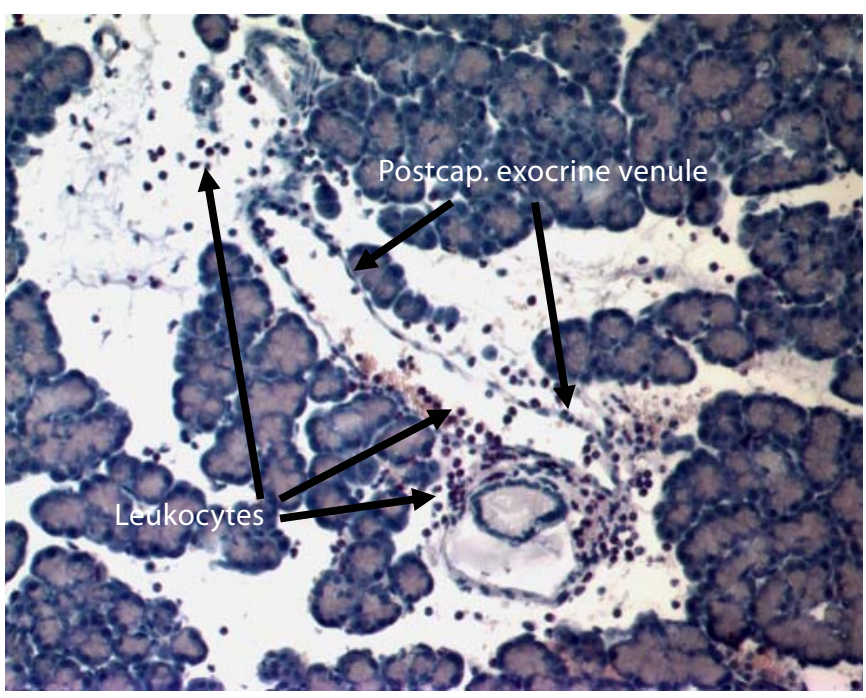

Fig. 5. Chloroacetate-esterase stained histological sections of pancreas grafts following $18 \mathrm{~h}$ hypothermic preservation and $2 \mathrm{~h}$ reperfusion. Left panel: multiple extravasated leukocytes surrounding a postcapillary exocrine venule, located within edema-

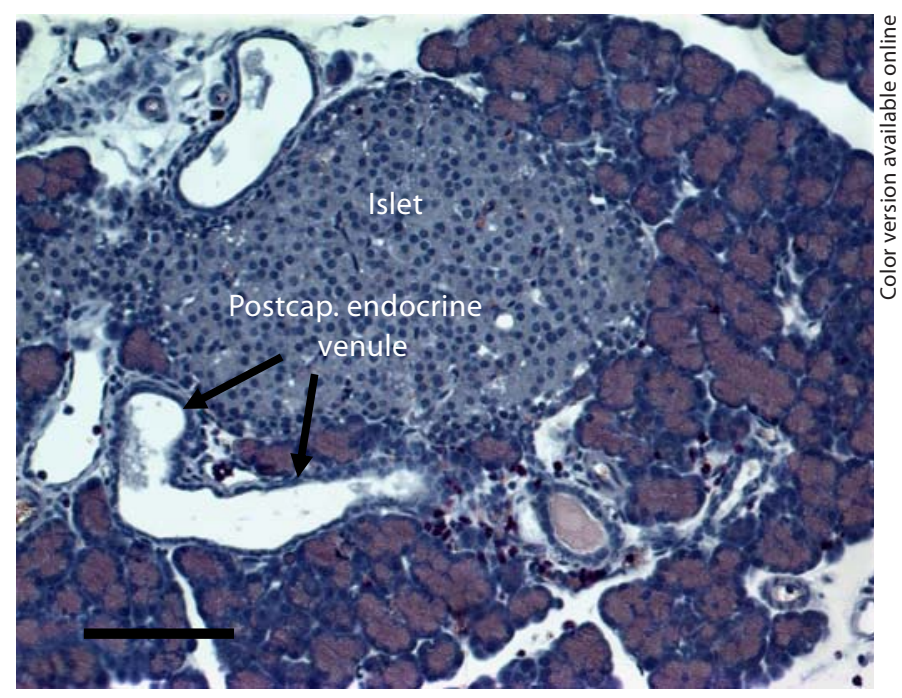

tous-altered pancreatic acini. Right panel: an islet of Langerhans with a closely attached postcapillary venule lacking leukocyte infiltration or edema formation. Bar $=100 \mu \mathrm{m}$. 
looked at postischemic capillary perfusion in endocrine and exocrine pancreas [15, 19], whereas postischemic leukocyte accumulation, an event known to be indispensable for the development of graft pancreatitis $[4,5,23]$, was not directly analyzed.

In accordance with other investigations $[3,4,19,23]$, we identified the duration of ischemia to be a major determinant of the extent of damage in exocrine tissue. A short period of $2 \mathrm{~h}$ hypothermic preservation was associated with only mild alterations to acinar tissue after transplantation. Albeit the limited extent of tissue damage, reperfusion after $2 \mathrm{~h}$ of ischemia was characterized by an immediate and significant rise of the fraction of rolling leukocytes followed by a slow decline over the 120 -min observation period. Among others, P-selectinmediated rolling resembles one of the first steps in LEI. In fact, it has been shown that P-selectin is mobilized rapidly from cytosolic reservoirs to the endothelial surface after hypoxic insults [24]. For pancreas transplantation this mechanism has been reported to be operative, finally leading to diminished graft microcirculation [25]. Although leukocyte rolling occurred, the impact of $2 \mathrm{~h}$ hypothermic ischemia apparently was not strong enough to escalate the inflammatory process further, since firmly adherent leukocytes revealed only a minor peak after 30 min of reperfusion. In parallel, histological analysis did not show relevant cellular infiltration, suggesting that transmigration of leukocytes was nearly absent in the $2 \mathrm{~h}$-I group. Edema formation was slightly higher than in the control group, yet this could be attributed at least in part to interstitial fluid absorbance during organ recovery and hypothermic storage.

In contrast to short-term ischemia, long-term hypothermic preservation of $18 \mathrm{~h}$ induced pronounced microcirculatory disturbances and tissue alterations to the exocrine pancreas already within the observation period of $2 \mathrm{~h}$. Notably, in clinical PTx especially those initial microcirculatory alterations have been found to determine the degree of graft damage developing in the further postoperative course $[12,26]$. Leukocyte rolling peaked early after reperfusion and declined thereafter. This decline in the leukocyte rolling fraction was paralleled by a steady increase of the number of firmly adherent leukocytes. Firm leukocyte adherence is a characteristic both during native- and graft-pancreatitis and can be attenuated by oxygen radical scavengers like superoxide dismutase or $\mathrm{N}$-acetylcysteine $[4,27]$. The trafficking molecules LFA-1 or MAC-1, expressed on blood leukocytes, as well as ICAM-1, present on the endothelium, have been shown to be essential for firm leukocyte adhesion in the inflamed pancreas $[5,28]$. In line with these intravital observations, histological analysis revealed that substantial numbers of leukocytes had invaded the exocrine pancreas only $2 \mathrm{~h}$ after reperfusion. Tissue infiltration by leukocytes was associated with enhanced edema formation, a process that is thought to involve both VCAM-1 and VEGF [29].

In striking contrast, the ILH were largely unaffected by the profound inflammatory responses observed in the exocrine pancreas. Even though endothelial cells in postcapillary ILH venules are known to express adhesion molecules including VCAM-1, ICAM-1, E- and P-selectin $[30,31]$, leukocyte rolling and adherence were encountered only incidentally after transplantation. Also, there was no evidence for significant leukocyte infiltration or edema formation in the endocrine tissue, respectively. Although we did not directly address the aforementioned molecular determinants of LEI, our findings suggest that the ILH are protected from microcirculatory recruitment of inflammatory cells in the early reperfusion period after PTx.

Several ILH-specific factors are decisive for their superior resistance against I/R. In addition to differences in the angioarchitecture, resembling a glomerulum-like vascular network [32], particularly the higher blood flow in ILH $[15,16]$ is striking when compared to the exocrine tissue. While ILH comprise only $1 \%$ of the pancreatic mass, they receive $5-15 \%$ of the organ blood supply [17, 33]. This preferential perfusion persists even after transplantation $[15,16]$. Additionally, diameters of postcapillary venules of the ILH are on average smaller when compared to postcapillary venules of the exocrine tissue. Higher blood flow in conjunction with smaller vessel diameters in ILH venules go along with augmented vascular shear rates in comparison to the acinar microcirculation. Therefore, increased shear forces antagonize adhesion forces between leukocytes and endothelial cells in venules of the ILH during graft reperfusion, thus preventing leukocyte accumulation [34]. Furthermore, vascular endothelium shows specific transcriptional patterns, once exposed to different types of blood flow-related mechanical forces [35-37]. High laminar shear stress can induce endothelial upregulation and expression of vasoprotective anti-inflammatory proteins such as eNOS and COX-2 via biomechanically inducible genes [35,38], while adhesion molecule expression remains inhibited [39]. Indeed, ILH displayed a high and largely continuous capillary perfusion, whereas an intermittent capillary flow was present in the exocrine pancreas after transplantation $[19,40]$. These differences in blood flow condi- 
tions within the exocrine and endocrine pancreas might be translated into differences of the endothelial phenotype, favoring leukocyte accumulation in the exocrine pancreas and opposing leukocyte adhesion in the ILH.

Additionally, the constitutive isoforms of nitric oxide synthase [41] and heme oxygenase [42] play an important role for blood flow regulation and hormone release in ILH. Apart from their vasodilating actions, both enzyme systems provoke antiadhesive and antioxidative actions via their products nitric oxide and carbon monoxide, respectively, thus potentially contributing to the augmented resistance of the ILH against I/R.

The present study provides basic information leading to a better understanding of perioperative alterations in pancreas grafts. We found a dissociation in the manifestation of the I/R injury between exocrine and endocrine tissue. The ILH remained almost unaffected by proinflammatory LEI or tissue damage in the early reperfusion period, indicating an elaborate resistance towards I/R in- jury. From a physiological point of view, specific protection of the islet apparatus is mandatory for the organism, since insulin-dependent blood glucose regulation is of central importance for survival. For the clinical situation our findings suggest that especially long-term preserved grafts should be monitored closely in the postoperative period, to identify and fight I/R-related organ damage at an early stage. Due to the higher resistance of the ILH, measurements of blood glucose concentrations and Cpeptide levels might indicate altered graft viability delayed in certain cases. Therefore, direct imaging techniques such as color-Doppler and contrast-enhanced ultrasonography [43] should be used as supplemental diagnostic tools in the postoperative course after pancreas transplantation. Further studies aimed at a better understanding of the mechanisms operative within the ILH, counteracting inflammatory attacks, could help to reduce the incidence of graft pancreatitis in the future.

\section{References}

1 Grewal HP, Garland L, Novak K, Gaber L, Tolley EA, Gaber AO: Risk factors for postimplantation pancreatitis and pancreatic thrombosis in pancreas transplant recipients. Transplantation 1993;56:609-612.

2 Gruessner AC, Sutherland DE: Pancreas transplant outcomes for United States (US) and non-US cases as reported to the United Network for Organ Sharing (UNOS) and the International Pancreas Transplant Registry (IPTR) as of June 2004. Clin Transplant 2005; 19:433-455.

3 Humar A, Ramcharan T, Kandaswamy R, Gruessner RWG, Gruessner AC, Sutherland DER: Technical failures after pancreas transplants: why grafts fail and the risk factors - a multivariate analysis. Transplantation 2004;78:1188-1192.

4 Mayer H, Schmidt J, Thies J, Ryschich E, Gebhard MM, Herfarth C, Klar E: Characterization and reduction of ischemia/reperfusion injury after experimental pancreas transplantation. J Gastrointest Surg 1999;3: 162-166.

5 Keck T, Werner J, Schneider L, Gebhard MM, Klar E: Characterization of ischemia/ reperfusion injury after pancreas transplantation and reduction by application of monoclonal antibodies against ICAM-1 in the rat. Surgery 2003;134:63-71.
6 Schaefer N, Tahara K, Schmidt J, Wehner S, Kalff JC, bu-Elmagd K, Hirner A, Turler A: Resident macrophages are involved in intestinal transplantation-associated inflammation and motoric dysfunction of the graft muscularis. Am J Transplant 2007;7:10621070.

7 Dong X, Swaminathan S, Bachman LA, Croatt AJ, Nath KA, Griffin MD: Resident dendritic cells are the predominant TNF-secreting cell in early renal ischemia-reperfusion injury. Kidney Int 2007;71:619-628.

8 Vonlaufen A, Apte MV, Imhof BA, Frossard JL: The role of inflammatory and parenchymal cells in acute pancreatitis. J Pathol 2007; 213:239-248.

9 Zarbock A, Ley K: Neutrophil adhesion and activation under flow. Microcirculation 2009; 16:31-42.

10 Neeff HP, von DE, Sommer O, Hopt UT, Drognitz O: In vivo quantification of oxygen-free radical release in experimental pancreas transplantation. Transplant Int 2008; 21:1081-1089.

11 Menger MD, Pelikan S, Steiner D, Messmer $\mathrm{K}$ : Microvascular ischemia-reperfusion injury in striated muscle: significance of 'reflow paradox'. Am J Physiol 1992;263:H1901H1906.

12 Benz S, Bergt S, Obermaier R, Wiessner R, Pfeffer F, Schareck W, Hopt UT: Impairment of microcirculation in the early reperfusion period predicts the degree of graft pancreatitis in clinical pancreas transplantation. Transplantation 2001;71:759-763.
13 Rocha SF, Adams RH: Molecular differentiation and specialization of vascular beds. Angiogenesis 2009;12:139-147.

14 Yao VJ, Ozawa MG, Trepel M, Arap W, McDonald DM, Pasqualini R: Targeting pancreatic islets with phage display assisted by laser pressure catapult microdissection. Am J Pathol 2005;166:625-636.

15 Jansson L, Carlsson PO, Bodin B, Andersson A, Kallskog O: Capillary blood pressure in the endocrine and exocrine parenchyma of rat pancreas transplants. Surgery 2001;129: 196-202.

16 Jansson L, Bodin B, Carlsson PO: Changes in graft blood flow early after syngeneic rat pancreas-duodenum transplantation. Ups J Med Sci 2005;110:57-67.

17 Johansson M, Carlsson PO, Bodin B, Andersson A, Kallskog O, Jansson L: Acute effects of a $50 \%$ partial pancreatectomy on total pancreatic and islet blood flow in rats. Pancreas 2005;30:71-75.

18 Secchi A, Pontiroli AE, Traeger J, Dubernard JM, Touraine JL, Ruitton A, Blanc N, Pozza G: A method for early detection of graft failure in pancreas transplantation. Transplantation 1983;35:344-348.

19 Vollmar B, Janata J, Yamauchi J, Wolf B, Heuser M, Menger MD: Exocrine, but not endocrine, tissue is susceptible to microvascular ischemia/reperfusion injury following pancreas transplantation in the rat. Transplant Int 1999; 12:50-55. 
20 Lee S, Tung KS, Koopmans H, Chandler JG, Orloff MJ: Pancreaticoduodenal transplantation in the rat. Transplantation 1972;13: 421-425.

21 Steinbauer M, Harris AG, Abels C, Messmer $\mathrm{K}$ : Characterization and prevention of phototoxic effects in intravital fluorescence microscopy in the hamster dorsal skinfold model. Langenbecks Arch Surg 2000;385: 290-298.

22 Vollmar B, Janata J, Yamauchi JI, Menger MD: Attenuation of microvascular reperfusion injury in rat pancreas transplantation by L-arginine. Transplantation 1999;67:950955.

23 Drognitz O, Obermaier R, Liu X, Neeff H, von Dobschuetz E, Hopt UT, Benz S: Effects of organ preservation, ischemia time and caspase inhibition on apoptosis and microcirculation in rat pancreas transplantation. Am J Transplant 2004;4:1042-1050.

24 Pinsky DJ, Naka Y, Liao H, Oz MC, Wagner DD, Mayadas TN, Johnson RC, Hynes RO, Heath M, Lawson CA, Stern DM: Hypoxiainduced exocytosis of endothelial cell Weibel-Palade bodies: a mechanism for rapid neutrophil recruitment after cardiac preservation. J Clin Invest 1996;97:493-500.

25 Keck T, Banafsche R, Werner J, Gebhard MM, Herfarth C, Klar E: Desmopressin impairs microcirculation in donor pancreas and early graft function after experimental pancreas transplantation. Transplantation 2001;72:202-209.

26 Schaser KD, Puhl G, Vollmar B, Menger MD, Stover JF, Kohler K, Neuhaus P, Settmacher $\mathrm{U}$ : In vivo imaging of human pancreatic microcirculation and pancreatic tissue injury in clinical pancreas transplantation. Am J Transplant 2005;5:341-350.

27 Kusterer K, Poschmann T, Friedemann A, Enghofer M, Zendler S, Usadel KH: Arterial constriction, ischemia-reperfusion, and leukocyte adherence in acute pancreatitis. Am J Physiol 1993;265:G165-G171.
28 Ramudo L, De D, I, Yubero S, Vicente S, Manso MA: ICAM-1 and CD11b/CD18 expression during acute pancreatitis induced by bile-pancreatic duct obstruction: effect of $\mathrm{N}$-acetylcysteine. Exp Biol Med (Maywood) 2007;232:737-743.

29 von DE, Meyer S, Thorn D, Marme D, Hopt UT, Thomusch O: Targeting vascular endothelial growth factor pathway offers new possibilities to counteract microvascular disturbances during ischemia/reperfusion of the pancreas. Transplantation 2006;82: 543-549.

30 Lou J, Triponez F, Oberholzer J, Wang H, Yu D, Buhler L, Cretin N, Mentha G, Wollheim CB, Morel P: Expression of alpha-1 proteinase inhibitor in human islet microvascular endothelial cells. Diabetes 1999;48:17731778.

31 Favaro E, Bottelli A, Lozanoska-Ochser B, Ferioli E, Huang GC, Klein N, Chiaravalli A, Perin PC, Camussi G, Peakman M, Conald PG, Zanone MM: Primary and immortalised human pancreatic islet endothelial cells: phenotypic and immunological characterisation. Diabetologia 2005;48:2552-2562.

32 Cabrera O, Berman DM, Kenyon NS, Ricordi C, Berggren PO, Caicedo A: The unique cytoarchitecture of human pancreatic islets has implications for islet cell function. Proc Natl Acad Sci USA 2006;103:2334-2339.

33 Menger MD, Yamauchi J, Vollmar B: Revascularization and microcirculation of freely grafted islets of Langerhans. World J Surg 2001;25:509-515.

34 Ji JY, Jing H, Diamond SL: Hemodynamic regulation of inflammation at the endothelial-neutrophil interface. Ann Biomed Eng 2008;36:586-595

35 Gimbrone MA, Jr, Topper JN, Nagel T, Anderson KR, Garcia-Cardena G: Endothelial dysfunction, hemodynamic forces, and atherogenesis. Ann NY Acad Sci 2000;902:230239.
36 Topper JN, Gimbrone MA Jr: Blood flow and vascular gene expression: fluid shear stress as a modulator of endothelial phenotype. Mol Med Today 1999;5:40-46.

37 Parmar KM, Larman HB, Dai G, Zhang Y, Wang ET, Moorthy SN, Kratz JR, Lin Z, Jain MK, Gimbrone MA Jr, Garcia-Cardena G: Integration of flow-dependent endothelial phenotypes by Kruppel-like factor 2. J Clin Invest 2006;116:49-58

38 Topper JN, Cai J, Falb D, Gimbrone MA Jr: Identification of vascular endothelial genes differentially responsive to fluid mechanical stimuli: cyclooxygenase-2, manganese superoxide dismutase, and endothelial cell nitric oxide synthase are selectively up-regulated by steady laminar shear stress. Proc Natl Acad Sci USA 1996;93:10417-10422.

39 Chiu JJ, Chen LJ, Lee PL, Lee CI, Lo LW, Usami S, Chien S: Shear stress inhibits adhesion molecule expression in vascular endothelial cells induced by coculture with smooth muscle cells. Blood 2003;101:2667-2674.

40 Preissler G, Massberg S, Waldner H, Messmer K: Intermittent capillary perfusion in rat pancreas grafts following short- and long-term preservation in University of Wisconsin solution. Transpl Int 2006;19:325332 .

41 Suschek CV, Bonmann E, Kolb-Bachofen V: A regulatory defect of constitutive no-synthase in islet endothelial cells correlates with probability of disease manifestation in BBdp rats. Diabetologia 1999;42:457-464.

42 Henningsson R, Alm P, Ekstrom P, Lundquist I: Heme oxygenase and carbon monoxide: regulatory roles in islet hormone release: a biochemical, immunohistochemical, and confocal microscopic study. Diabetes 1999; 48:66-76.

43 Boggi U, Morelli L, Amorese G, Bargellini I, Marchetti P, Mosca F: Contribution of contrast-enhanced ultrasonography to nonoperative management of segmental ischemia of the head of a pancreas graft. Am J Transplant 2009;9:413-418. 